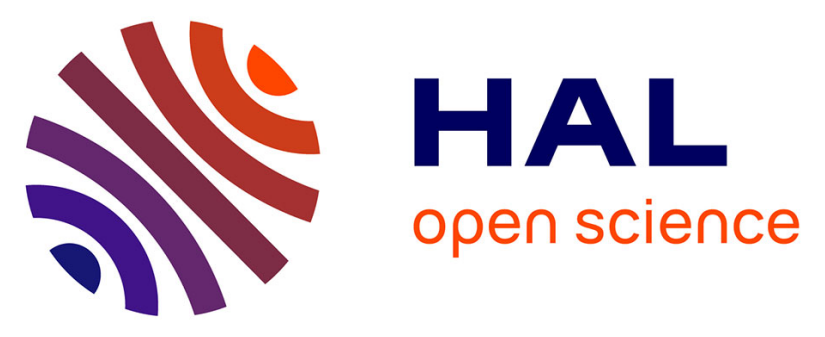

\title{
Enhancing Nab-Paclitaxel Delivery Using Microbubble-Assisted Ultrasound in a Pancreatic Cancer Model
}

Diane Bressand, Anthony Novell, Alban Girault, William Raoul, Gaëlle Fromont-Hankard, Jean-Michel Escoffre, Thierry Lecomte, Ayache Bouakaz

\section{To cite this version:}

Diane Bressand, Anthony Novell, Alban Girault, William Raoul, Gaëlle Fromont-Hankard, et al.. Enhancing Nab-Paclitaxel Delivery Using Microbubble-Assisted Ultrasound in a Pancreatic Cancer Model. Molecular Pharmaceutics, 2019, 16 (9), pp.3814-3822. 10.1021/acs.molpharmaceut.9b00416 . hal-02301225

\section{HAL Id: hal-02301225 \\ https://hal.science/hal-02301225}

Submitted on 17 Jan 2020

HAL is a multi-disciplinary open access archive for the deposit and dissemination of scientific research documents, whether they are published or not. The documents may come from teaching and research institutions in France or abroad, or from public or private research centers.
L'archive ouverte pluridisciplinaire HAL, est destinée au dépôt et à la diffusion de documents scientifiques de niveau recherche, publiés ou non, émanant des établissements d'enseignement et de recherche français ou étrangers, des laboratoires publics ou privés. 


\title{
Enhancing Nab-paclitaxel delivery using
}

\section{microbubble-assisted ultrasound in a pancreatic}

\section{cancer model}

\author{
D. Bressand ${ }^{a, b}$, A. Novell ${ }^{a}$, A. Girault ${ }^{b}$, W. Raoul ${ }^{b}$, G. Fromont ${ }^{c}$, \\ J-M. Escoffre $a^{a^{*}}$, T. Lecomte $b^{b^{*}}$, A. Bouakaz ${ }^{a^{*}}$
}

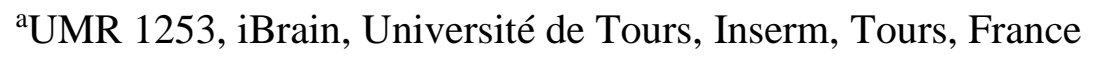

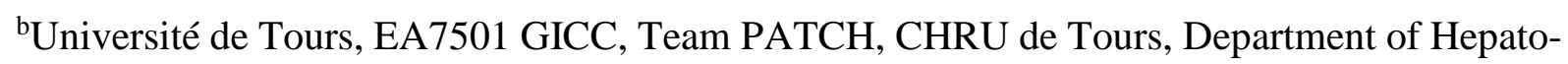
gastroenterology and Digestive Cancerology, Tours, France

'Université de Tours, Inserm, UMR 1069, Nutrition, Croissance, Cancer, CHRU de Tours, Department of Pathological Anatomy and Cytology, Tours, France

*T. Lecomte \& A. Bouakaz contributed equally to this work.

\section{RUNNING TITLE}

Ultrasound-assisted Nab-paclitaxel delivery.

\section{Corresponding Author}

*J-M Escoffre, Ph.D., UMR 1253, iBrain, Université de Tours, Inserm, 10 boulevard Tonnellé, 37032 Tours, France. Tel: +33(0)247366191. Email address: jean-michel.escoffre@univtours.fr and T. Lecomte., M.D., Université de Tours, EA7501 GICC, Team PATCH, CHRU de Tours, Department of Hepato-gastroenterology and Digestive Cancerology, 10 boulevard Tonnellé, 37032 Tours, France. Tel: +33(0)247366079. Email address: thierry.lecomte@univtours.fr. 


\section{ABSTRACT}

The combination of microbubbles and ultrasound is an emerging method for non-invasive and targeted enhancement of anticancer drugs uptake. This method showed to increase local drug extravasation in tumor tissue while reducing the systemic adverse effects in various tumor models. The present study aims into evaluating the therapeutic efficacy of this approach both in-vitro and in-vivo for Nab-paclitaxel delivery in a pancreatic tumor model. Ultrasound and microbubbles of different types in combination with Nab-paclitaxel showed a significant decrease in cell viability of human pancreatic cancer cells in comparison with Nab-paclitaxel treatment alone in in-vitro scenario. In-vivo, the results demonstrated that ultrasound and microbubbles in combination with Nab-paclitaxel induced a significant decrease in tumor growth in subcutaneous pancreatic adenocarcinoma xenograft model in nude mice in comparison to tumors treated with Nab-paclitaxel alone. The post-mortem anatomopathological analyses of tumor tissues partially confirmed these results. In conclusion, this study demonstrates that microbubble-assisted ultrasound is a promising method to improve the therapeutic efficacy of Nab-paclitaxel in a pancreatic cancer model.

KEYWORDS: Pancreatic cancer - Nab-paclitaxel - microbubble - ultrasound - sonoporation. 


\section{INTRODUCTION}

Pancreatic cancer is the $9^{\text {th }}$ most commonly diagnosed cancer in the European Union ${ }^{1}$ and is currently the $4^{\text {th }}$ leading cause of cancer-related death in the $\mathrm{EU}^{2}$. Recently, Ferlay et al., reported that more deaths from pancreatic cancer will occur than breast cancer $(91,500$ versus 91,000 annual deaths) in the $\mathrm{EU}^{3}$. By 2025, deaths from pancreatic cancer are predicted to be $25 \%$ higher than for breast cancer (111,500 and 90,000, respectively). Pancreatic cancer may become the $3^{\text {rd }}$ leading cause of death from cancer in the EU after lung and colorectal cancers. For patients diagnosed with pancreatic cancer, the 5-year survival rate is poor (about 3\%-15\%). Drug resistance, high metastasis occurrence, poor prognosis and tumor relapse contributed to the difficulties in treating pancreatic cancer.

Nab-paclitaxel (injectable formulation of nanoparticle albumin-bound paclitaxel $)^{4}$ in combination with gemcitabine, or 5-fluorouracil/leucovorin in combination with irinotecan plus oxaliplatin (FOLFIRINOX) represents major advances for the treatment of metastatic pancreatic cancer over gemcitabine alone, providing each ones almost identical disease control and similar survival rates ${ }^{5,67}$. Furthermore, FOLFIRINOX regimen may be particularly toxic and the adverse events may be more severe compared with those observed with therapy using Nab-paclitaxel plus gemcitabine ${ }^{8,9}$. Thus, gemcitabine monotherapy or combined with Nabpaclitaxel is the standard care in patients with poor performance status or contraindication to FOLFIRINOX protocol. Efficacy of chemotherapy for pancreatic cancer is far from satisfactory and one of the reasons is the complex tumor microenvironment which decreases effective drug extravasation to target cancer cell. Systemic chemotherapies are also associated with significant off-target effects due to the unspecific nature of these therapies. To overcome these limitations, the development of targeted drug delivery methods is required to increase the intratumoral concentration of chemotherapeutic agents while minimizing side effects to healthy tissues related to the systemic chemotherapy. Such methods might have a great potential as neo- 
adjuvant and/or palliative pancreatic cancer treatments by decreasing tumor burden and hence either facilitate surgical resection or provide symptom relief.

Microbubble-assisted ultrasound (also known as sonoporation) is receiving increasing attention as a physical innovative delivery method of therapeutic compounds, including chemotherapeutic agents, nucleic acids and antibodies ${ }^{10-12}$. This approach involves the ultrasound activation of gas-filled microbubbles (MBs) in the vicinity of the biological barriers (e.g., endothelial barriers, plasma membrane) to reversibly enhance their permeability ${ }^{13}$. The MB acoustic behavior in the vicinity of biological barriers depends on the acoustic parameters ${ }^{14}$. As previously reported, stable and inertial cavitations induced physical phenomena including microstreaming ${ }^{15,16}$, shock waves ${ }^{17,18}$ and microjets ${ }^{19}{ }^{20}$, which might transiently enhance the extravasation and the intracellular uptake of therapeutic compounds through the generation of membrane pores and/or the stimulation of paracellular and transcellular pathways ${ }^{21,22}$. Thus, microbubble-assisted ultrasound offers great promise in improving the therapeutic effectiveness of a chemotherapeutic agent by increasing their local deposition into the tumor tissues and reducing their systemic side effects on healthy tissues ${ }^{23}$.

Few previous preclinical ${ }^{24,25}$ as well as clinical studies ${ }^{10,26}$ reported that microbubbleassisted ultrasound increased the therapeutic effectiveness of anticancer drugs, such as gemcitabine, compared to the systemic chemotherapeutic alone. Given the recent clinical progress in pancreatic adenocarcinoma cytotoxic therapy, our present study thus explored the efficiency of microbubble-assisted ultrasound to deliver a rather large drug-loaded nanoparticle, Nab-paclitaxel (130 $\mathrm{nm}$ in diameter). The aim of the present study is therefore to investigate whether the combination of ultrasound and microbubble is able to deliver of Nabpaclitaxel. Hence, we investigated the in-vitro and in-vivo therapeutic potential of acousticallymediated Nab-paclitaxel delivery in human pancreatic cancer model. 


\section{EXPERIMENTAL SECTION}

\section{Chemicals and microbubbles}

Nab-paclitaxel (Celgene, Courbevoie, France) was a generous gift from Dr. J.F. Tournamille (Regional Center of Cancerology, Henry Kaplan, CHRU de Tours, Tours, France). The clinical dose of Nab-paclitaxel is $40 \mathrm{mg} / \mathrm{kg}^{27}$. All microbubbles have been kindly offered by Bracco Suisse S.A. (Geneva, Switzerland). BG8214 contrast agents were used for both contrastenhanced ultrasound imaging and acoustically-mediated drug delivery ${ }^{28,29 .}$ The microbubbles consist of a gaseous core of nitrogen and perfluorobutane mixture surrounded by PEGylated phospholipid shell. BG8610 microbubbles show similar characteristics as Bracco's formulation described in Schneider et $\mathrm{al}^{30}$.

\section{Cell Culture}

Human pancreatic adenocarcinoma cells BxPC-3 were kindly provided by Prof. F.X. CaroliBosc (Department of Hepato-gastro-enterology and digestive oncology, CHRU d'Angers, Angers, France). This cell line was derived from a pancreatic ductual adenocarcinoma. BxPC3 cells were grown as a monolayer in Roswell Park Memorial Institute Medium 1640 (RPMI 1640; Sigma-Aldrich ${ }^{\mathrm{TM}}$, St. Louis, MO) supplemented with 10\% fetal calf serum (FCS; Eurobio, Courtaboeuf, France) and with $1 \%$ penicillin and streptomycin mixture (ThermoFisher Scientific, Waltham, MA). The cells were routinely subcultured every 3 days at $37^{\circ} \mathrm{C}$ in a humidified atmosphere in a $5 \% \mathrm{CO}_{2}$ incubator.

\section{Ultrasound setup}

Ultrasound waves were generated using a single-element ultrasound transducer (Sofranel, Sartrouville, France) with a center frequency of $1 \mathrm{MHz}$. The transducer had a diameter of 15 $\mathrm{mm}$ and was naturally focused at $25 \mathrm{~mm}$. It was driven by an electrical signal generated from an arbitrary waveform generator (Agilent, Santa Clara, CA), then amplified by a power amplifier (ADECE, Artannes sur Indre, France). The peak negative pressure was measured in 
a separate setup using a calibrated hydrophone (HGL200, ONDA, Sunnyvale,CA) at the natural focal distance of the transducer.

\section{Membrane permeabilization to small molecules}

Cell membrane permeabilization to small molecules was assessed with propidium iodide (PI), a non-permeant molecule (final concentration $100 \mu \mathrm{M}$; $669.39 \mathrm{Da}$; hydrodynamic radius $\sim 0.6$ $\mathrm{nm})^{31,32}$. BxPC-3 cells were harvested using $0.25 \%$ trypsin-EDTA (ThermoFisher Scientific, Waltham, MA) and resuspended in OptiMEM ${ }^{\circledR}$ High W/GlutaMAX-1 (ThermoFisher Scientific, Waltham, MA) supplemented with $1 \%$ FCS. The cell viability was assessed using Trypan Blue exclusion assay and was around 98\%. During the procedure, the cell suspension $\left(5 \times 10^{5}\right.$ cells in $\left.1.5 \mathrm{~mL}\right)$ was maintained in water bath at $37^{\circ} \mathrm{C}$ (Grant Instruments Ltd., Cambridge, UK). Then, it was placed in a polystyrene cuvette $(45 \mathrm{~mm}$ height, $10 \mathrm{~mm}$ inner diameter, $12 \mathrm{~mm}$ outer diameter; ThermoFisher Scientific, Waltham, MA). PI (0.1 mL) and gas microbubbles (microbubble-to-cell ratio of 5) was added just before ultrasound application. The center of the plastic cuvette was positioned at the focal distance of the transducer in a deionized water tank at $37^{\circ} \mathrm{C}$. The cell suspension was kept uniform through a gentle magnetic stirring during ultrasound application. Subsequently, the cell suspension was exposed to $1 \mathrm{MHz}$ sinusoidal ultrasound waves with a pulse repetition period of $100 \mu \mathrm{s}, 40$ cycles per pulse (i.e., $40 \%$ duty cycle, where the signal is on $40 \mu$ s and off on $60 \mu \mathrm{s}$ ) for a total exposure time of 30 seconds (i.e., optimal acoustic parameters for in-vitro gene and drug delivery) ${ }^{33,34}$. The applied acoustic pressure (i.e., peak negative pressure) was set to $400 \mathrm{kPa}$.

Fifteen minutes later, the permeabilization level (i.e., percentage of PI-positive cells) was assessed by flow cytometry ${ }^{33}$. Fluorescence histograms were recorded using a flow cytometer (Beckman Coulter Inc., Fullerton, CA) and analyzed using the Kaluza software supplied by the manufacturer. A minimum of 10000 events was analyzed to generate each histogram. The gate was arbitrary set for the detection of red fluorescence intensity. 


\section{Membrane permeabilization to fluorescent nanoparticles}

Using the same in-vitro set-up and procedure as previously described for PI delivery, membrane permeabilization to $150 \mathrm{~nm}$ DiagnNano $^{\mathrm{TM}}$ green fluorescent silica nanoparticles (final concentration: $50 \mathrm{mg} / \mathrm{mL}$; Creative Diagnostics, Shirley NY) was assessed. These nanoparticles were used as similar size particles to Nab-paclitaxel. Fifteen minutes after ultrasound application, the cell suspension was twice centrifuged (i.e., $3 \mathrm{~min}, 300 \mathrm{~g}$ ) and resuspended in $300 \mu \mathrm{L}$ Dulbecco's phosphate-buffered saline solution (ThermoFisher Scientific, Waltham, MA) supplemented with 1\% FCS. As described above, permeabilization level (i.e., percentage of nanoparticle-positive cells) was assessed by flow cytometry.

\section{In-vitro Nab-paclitaxel delivery}

Using the procedure previously described for in-vitro delivery of fluorescent nanoparticles, Nab-paclitaxel (Celgene SARL, Paris, France) delivery was assessed using the same ultrasound settings. A final concentration of $2.5 \mathrm{ng} / \mathrm{mL}$ Nab-paclitaxel was chosen based on in-vitro preliminary unpublished data. After ultrasound application, $500 \mu \mathrm{L}$ of cells were cultured in a 24 well cell culture plates (Corning Life Science BV, Amsterdam, the Netherlands) and incubated at $37^{\circ} \mathrm{C}$ in a humidified atmosphere with a $5 \% \mathrm{CO}_{2}$ incubator. Four hours later, 500 $\mu \mathrm{L}$ of OptiMEM High W/GlutaMAX-1 supplemented with $19 \%$ FCS and with $2 \%$ penicillin and streptomycin mixture was added to each well and incubated at $37^{\circ} \mathrm{C}$ in a humidified atmosphere with a $5 \% \mathrm{CO}_{2}$ incubator for $72 \mathrm{hrs}$.

\section{Cell viability}

The cell viability was evaluated using a methylthiazolydiphenyltetrazolium bromide (MTT) colorimetric assay. Forty-eight and seventy-two hours after treatment, the cell medium was replaced with a $0.5 \mathrm{mg} / \mathrm{mL}$ MTT solution (ThermoFisher Scientific, Waltham, MA) and the cells were incubated at $37^{\circ} \mathrm{C}$ in a humidified atmosphere with a $5 \% \mathrm{CO}_{2}$ incubator for 1 hour. Afterward, the MTT solution was substituted by pure dimethyl sulfoxide solution (Sigma- 
Aldrich, St. Louis, MO) and the cells were incubated for 10 min under gentle stirring (i.e., 20 $\mathrm{rpm})$ at room temperature. The optical density (OD) was then measured at $570 \mathrm{~nm}\left(\mathrm{OD}_{570}\right)$ to determine the amount of formed formazan crystals and at $690 \mathrm{~nm}\left(\mathrm{OD}_{690}\right)$ as a reference using a spectrophotometer (Mithras LB940, Berthold technologies, Badwildbad, Germany). The cell viability was calculated as:

$$
\text { Cell viability }=\frac{\left(O D_{570} x-O D_{690} x\right)}{\left(O D_{570} \text { control }-O D_{690} \text { control }\right)} \times 100
$$

\section{In-vivo Nab-paclitaxel delivery}

All procedures were performed according to the ethical guidelines and were approved by the Animal Care and Regional Committee for Ethics in Animal Experiments, Val-de-Loire (No. 2017020117591464). Male Balb/c nude mice were purchased from Envigo (Gannat, France). Mice were maintained at constant room temperature with $12 \mathrm{~h}$ light cycle in a ventilated isolation cages. At the beginning of the experiments, mice were 6 weeks old, weighing 20-30 g. Food and water were present ad libitum. Mice were weighted twice a week during the whole therapeutic planning.

All experiments were performed under a sterile biosafety cabinet. The mice were anesthetized by $3 \%$ isoflurane (Isoflo, Coveto, Limoges, France) and oxygen via a facial oxygen mask in place throughout the procedure. This anesthesia was limited to $30 \mathrm{~min}$, and a thermostatically controlled pad (FUJIFILM-Visualsonics, Toronto, Canada) was used to maintain body temperature at about $37^{\circ} \mathrm{C}$. Under gaseous anesthesia, BxPC-3 cells $\left(5 \times 10^{6}\right.$ cells in $100 \mu \mathrm{L}$ PBS) were subcutaneously injected in each flank of the mouse.

As previously described ${ }^{29}$, the tumor perfusion was assessed using contrast-enhanced ultrasound imaging. Then, a total of 40 mice were divided into 7 experimental groups (8-9 mice/group) (Table 1). Under gaseous anesthesia, tumor treatment was initiated when the whole tumor was perfused and reached a volume of $50 \mathrm{~mm}^{3}$ (Day 0). It consisted of a direct i.v. administration of Nab-paclitaxel (or saline) via penile vein (5 or $20 \mathrm{mg} / \mathrm{kg} \mathrm{b.w.)} \mathrm{followed}$ 
immediately by a direct i.v. bolus injection of gas microbubbles $(70 \mu \mathrm{L}$ for each type of microbubble). The tumor was covered with ultrasound transmission gel and exposed to $1 \mathrm{MHz}$ sinusoidal ultrasound waves with a pulse repetition period of $100 \mu \mathrm{s}, 40$ cycles per pulse (i.e., $40 \%$ duty cycle), at a peak-negative pressure of $400 \mathrm{kPa}$ for a period of $3 \mathrm{mins}$. The treatment was performed twice a week until protocol endpoints are reached (i.e., 5.5 weeks).

Table 1. Design of experimental groups

\begin{tabular}{|l|l|l|l|l|l|l|l|}
\hline & Group 1 & Group 2 & Group 3 & Group 4 & Group 5 & Group 6 & Group 7 \\
\hline Nab- & - & - & $5 \mathrm{mg} / \mathrm{kg}$ & $5 \mathrm{mg} / \mathrm{kg}$ & $20 \mathrm{mg} / \mathrm{kg}$ & $20 \mathrm{mg} / \mathrm{kg}$ & $20 \mathrm{mg} / \mathrm{kg}$ \\
\hline paclitaxel & BG8214 & - & + & - & + & - & + \\
\hline BG8610 & - & - & - & - & - & - & - \\
\hline US & - & + & - & + & - & + & + \\
\hline
\end{tabular}

Anatomical ultrasound imaging

Tumor dimensions were determined using ultrasound imaging (Vevo 2100 System, Visualsonics-Fujifilm Inc., Toronto, Canada) at $21 \mathrm{MHz}$ (MS-250) and $40 \mathrm{MHz}$ (MS-550). Ultrasound B-scans were used to image the subcutaneous tumors and to measure the tumor dimensions over the therapeutic procedure. The tumor volume was assessed using the formula ${ }^{29}$ :

$$
\text { Tumor volume }=\frac{\text { length } \times \text { width } \times \text { thickness }}{2}
$$

\section{Quality of mouse life}

To evaluate the quality of life, variations in mouse behavior (i.e., respiratory deficiency, loss of locomotion, loss of appetite, etc) and in body weight were analyzed twice a week during the study.

\section{Immunohistochemistry}


All tumors were removed and fixed in $10 \%$ formalin for $24 \mathrm{hrs}$. Samples were then embedded in paraffin and cut in $3 \mu \mathrm{m}$ tissue sections. As previously described ${ }^{35}$, one section was stained with haematoxylin-eosin-safran (HES) in order to measure the size of the neoplastic nodule with a microscope and a micrometer and to determine the percentage of necrosis in the whole section (5-9 tumors/group) as performed in today practice when cancer necrosis has a prognostic value.

For immunohistochemical staining, slices were deparaffinized, rehydrated, and heated in citrate buffer $\mathrm{pH} 6$ for antigenic retrieval. After blocking for endogenous peroxidase with 3\% hydrogen peroxide, the primary antibody directed against the proliferation marker Ki67 (DakoCytomation, Glostrup, Denmark) was incubated $30 \mathrm{~min}$ at dilution 1:50. Immunohistochemistry was performed using the streptavidin-biotin-peroxidase method with diaminobenzidine as the chromogen (Kit LSAB, Dakocytomation). Slices were finally counterstained with haematoxylin. Ki67 positive cells were expressed as a percentage of total cancer cells. Slices were analyzed by an expert pathologist (GF).

\section{Statistical analysis}

Descriptive analysis was performed using GraphPad Prism v.6.0a (GraphPad Soltware Inc, La Jolla, CA, USA). Statistical analysis was performed using the non-parametric Mann-Whitney U test (significance was defined as $p<0.05$ ).

\section{RESULTS}

\section{In-vitro Nab-paclitaxel delivery}

The cell viability was assessed by the MTT assay $72 \mathrm{hrs}$ after Nab-paclitaxel delivery with or without microbubble-assisted ultrasound, and the results are shown in Figure 1A. The exposure of BxPC-3 cells to ultrasound at $400 \mathrm{kPa}$ in presence of BG8610 and BG8214 did not modify the cell viability in comparison to the control condition. As shown in Figure 1A, when the pancreatic adenocarcinoma cells were only treated with $2.5 \mathrm{ng} / \mathrm{mL}$ of Nab-paclitaxel, the cell 
viability significantly decreased compared to the control condition without Nab-paclitaxel (61 $\pm 2 \%$ vs $100 \pm 0.1 \% ; p<0.001)$. BxPC-3 cells treated with Nab-paclitaxel at $2.5 \mathrm{ng} / \mathrm{mL}$ and exposed to ultrasound in the presence of BG8610 microbubbles showed a slight but nonsignificant decrease in their viability in comparison to the treatment with Nab-paclitaxel alone. The combination of ultrasound and BG8214 microbubbles with $2.5 \mathrm{ng} / \mathrm{mL}$ of Nab-paclitaxel induced a significant decrease in the cell viability compared to the Nab-paclitaxel treatment alone $(50 \pm 2 \%$ vs $61 \pm 2 \% ; p<0.01)$. All together, these results clearly show that BG8214 microbubble in combination with ultrasound and Nab-paclitaxel induced a higher cell mortality compared to Nab-paclitaxel treatment alone.

A

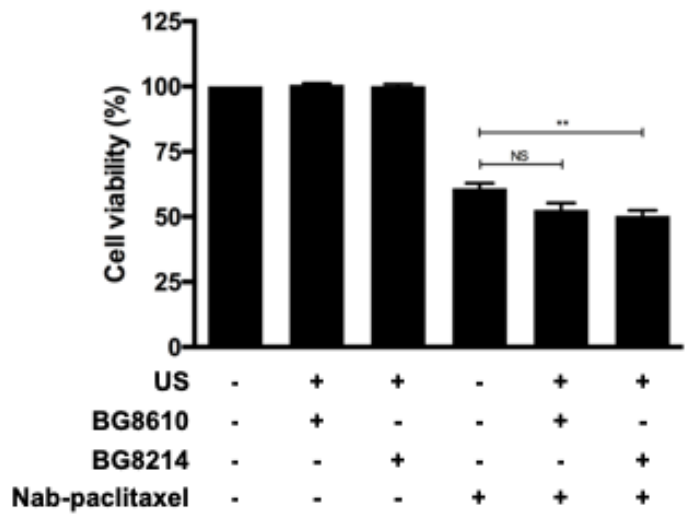

B

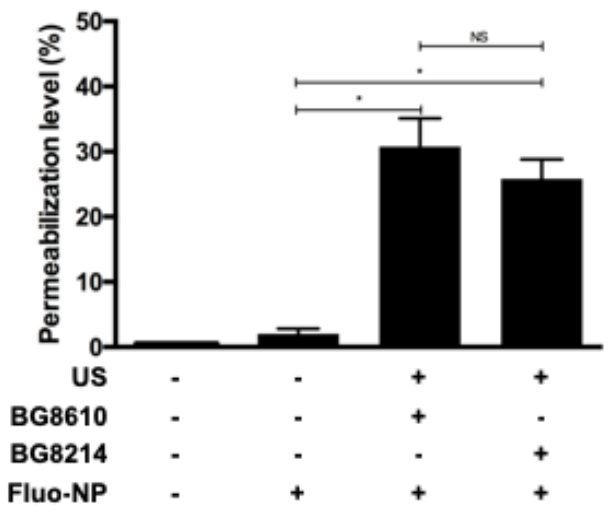

C

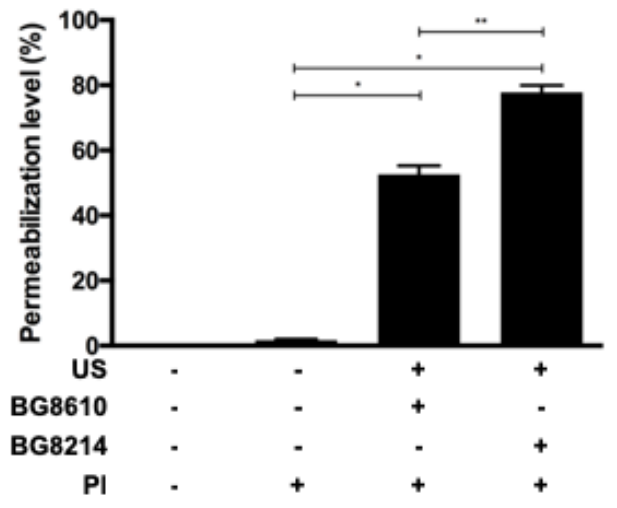

Figure 1. In-vitro Nab-paclitaxel delivery using microbubble-assisted ultrasound. BXPC3 cells were incubated with Nab-paclitaxel, fluorescent nanoparticles or propidium iodide on its own or combined with ultrasound at $400 \mathrm{kPa}$ for $30 \mathrm{~s}$ and BG8214 or BG8610 microbubbles. 
Seventy-two hours after treatment, cell viability was measured by a MTT assay (A). The intracellular uptake of fluorescent nanoparticles (B) and propidium iodide (C) was monitored by flow cytometry 10 min after sonoporation. Data expressed as mean \pm SEM were calculated from five independent experiments. Significance was defined as $p<0.05(* p<0.05 ; * * p<$ 0.01; Mann-Whitney test).

\section{Effects of BG8610 and BG8214 on cell permeabilization}

The permeabilization of the cell membrane is a key step for in-vitro drug delivery using microbubble-assisted ultrasound and strongly depends on the microbubble properties (e.g., type, dose, etc.). To gain insight into the effect of BG8610 and BG8214 microbubbles in combination with ultrasound on the membrane permeability of BxPC-3 cells, the acoustically-mediated membrane permeabilization to fluorescent nanoparticles was assessed using flow cytometry. Figure 1B indicates that the permeabilization level of BxPC-3 cells to the fluorescent nanoparticles (Fluo-NPs) was not statistically different from the control condition. This result suggests that the simple incubation of Fluo-NPs with BxCP-3 cells did not lead to their intracellular uptake. However, the exposure of the cells to ultrasound in the presence of microbubbles and Fluo-NPs induced a significant increase in the permeabilization level to FluoNPs compared to the Fluo-NPs incubation alone $(31 \pm 2 \%$ with BG8610 and $26 \pm 2 \%$ with BG8214 vs $2 \pm 0.5 \% ; p<0.05$ ). No significant difference was observed in the efficacy of BG8610 and BG8214 microbubbles to permeabilize the BxPC-3 cells to Fluo-NPs.

Considering that the acoustically-mediated membrane permeabilization is commonly monitored using small and non-permeant molecule ${ }^{36,37}$ such as propidium iodide, effects of BG8610 and BG8214 microbubbles on membrane permeability of BxPC-3 cells were assessed by intracellular uptake of propidium iodide using flow cytometry. As depicted in Figure 1C, the permeabilization level to propidium iodide is $2 \pm 0.01 \%$ in absence of ultrasound, indicating likely that these cells internalizing propidium iodide are presumably dead ${ }^{36}$. In agreement with 
previous investigations ${ }^{38,39}$, the permeabilization level to propidium iodide significantly increased using ultrasound and microbubbles $(p<0.05)$. As illustrated in Figure 1C, BG8214 microbubbles were more efficient than BG8610 microbubbles to induce membrane permeabilization to small and non-permeant molecule $(78 \pm 1 \%$ vs $53 \pm 1 \%$; $p<0.01)$ and both of them did not affect the cell viability (Figure 1A).

\section{In-vivo Nab-paclitaxel delivery}

As described in Table 1, subcutaneous pancreatic cancer tumors were treated with either BG8214 microbubble-assisted ultrasound on its own (Group 2), or i.v. administration of one Nab-paclitaxel dose at 5 (Group 3) or $20 \mathrm{mg} / \mathrm{kg}$ (Group 5) on its own, or by i.v. injection of one Nab-paclitaxel dose at 5 (Group 4) or $20 \mathrm{mg} / \mathrm{kg}$ (Group 6) in combination with microbubbleassisted ultrasound using BG8214 microbubbles, or by i.v. administration of one Nab-paclitaxel dose at $20 \mathrm{mg} / \mathrm{kg}$ in combination with microbubble-assisted ultrasound using BG88610 microbubbles (Group 7). In addition, a group of subcutaneous pancreatic cancer tumors were not treated and considered as control group (Group 1). The therapeutic effectiveness of Nabpaclitaxel delivery with or without microbubbles and ultrasound was monitored using anatomical ultrasound imaging every 3 day before the treatment ${ }^{29}$.

As shown in Figure 2A, BG8214 microbubble in combination with ultrasound application did not affect the tumor growth compared to the control group (Group 2 vs Group $1 ; p>0.05$ ). In addition, the repeated i.v. administration of one Nab-paclitaxel dose at $5 \mathrm{mg} / \mathrm{kg}$ on its own led to a significant decrease in the tumor volume compared to control group (Figures $2 \mathrm{~A}$ and 2B; Group 3 vs Group 1; $p<0.05$ ). Furthermore, the combination of Nab-paclitaxel with BG8214 microbubbles and ultrasound induced a significant and additional decrease in tumor volume after three treatments in comparison to Nab-paclitaxel treatment alone (Figure 2B; Group $4 v s$ Group 3; $p<0.05)$. As shown in Figure 2C, the repeated i.v. injection of one Nabpaclitaxel dose at $20 \mathrm{mg} / \mathrm{kg}$ on its own resulted in a significant decrease in tumor volume 
compared to the repeated delivery of a Nab-paclitaxel dose at $5 \mathrm{mg} / \mathrm{kg}$ on its own or in combination with BG8214 microbubble-assisted ultrasound (Group 5 vs Groups 3 and 4; $p<$ 0.01). The repeated delivery of one Nab-paclitaxel dose at $20 \mathrm{mg} / \mathrm{kg}$ in combination with BG8214 microbubble-assisted ultrasound led to a slight but statistically significant decrease in tumor volume compared to the $20 \mathrm{mg} / \mathrm{kg}$ Nab-paclitaxel treatment alone (Figure 2C; Group 6 vs Group 5; $p<0.05)$. However, the combination of this chemotherapy with BG8610 microbubble-assisted ultrasound resulted in a significant reduction in tumor volume until the $8^{\text {th }}$ treatment in comparison to the $20 \mathrm{mg} / \mathrm{kg} \mathrm{Nab}$-paclitaxel treatment alone (Figure 2C; Group $7 v s$ Group 5; $p$ 0.05). No significant difference in the therapeutic effectiveness was observed between both types of microbubbles for the repeated delivery of one Nab-paclitaxel dose at 20 $\mathrm{mg} / \mathrm{kg}$ (Figure 2C; Group 6 vs Group 7). These results suggest that microbubble-assisted ultrasound potentiate the therapeutic effectiveness of one Nab-paclitaxel dose at $5 \mathrm{mg} / \mathrm{kg}$ as well as at $20 \mathrm{mg} / \mathrm{kg}$ in subcutaneous pancreatic cancer mouse model.
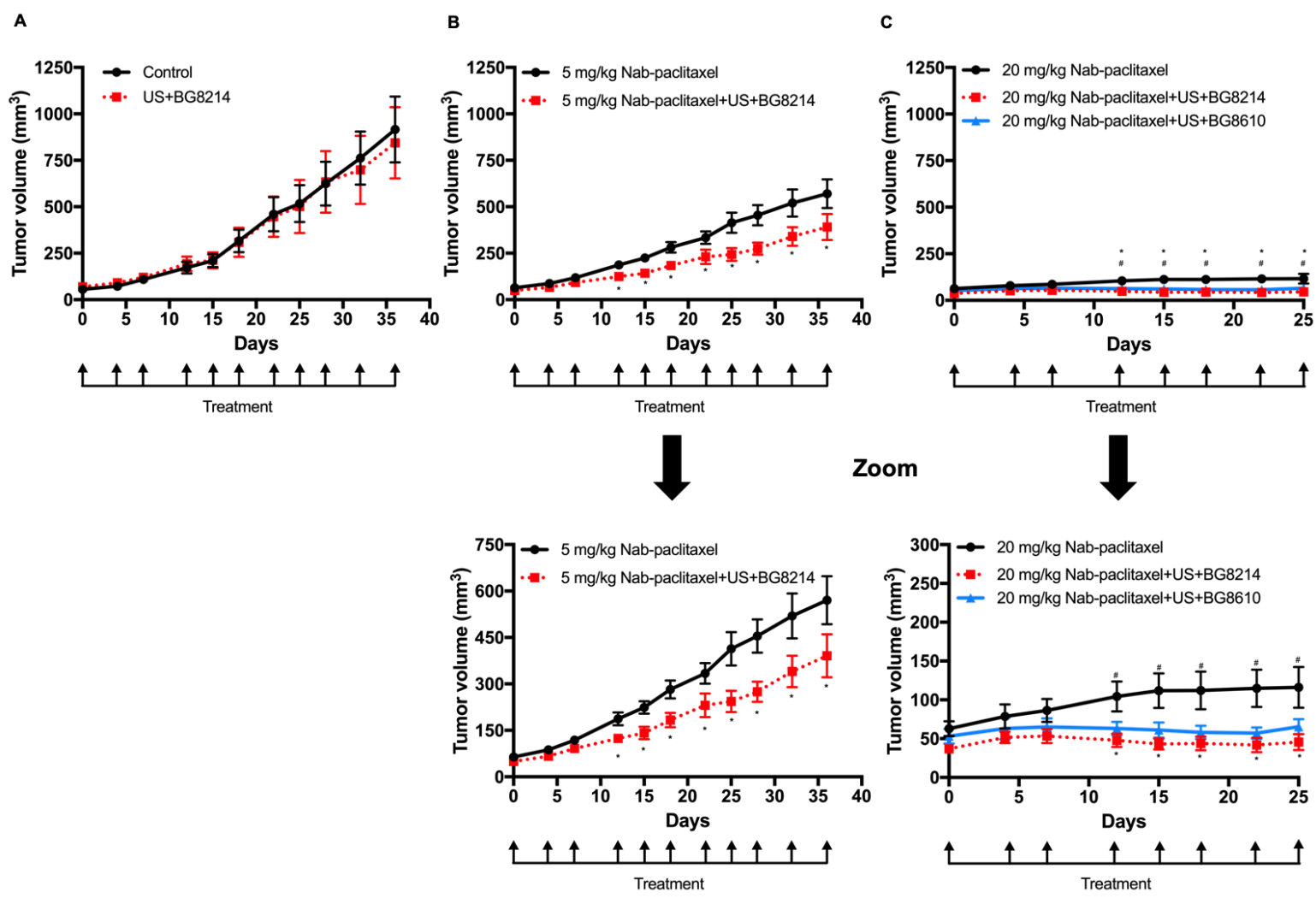


\section{Figure 2. In-vivo Nab-paclitaxel delivery using microbubble-assisted ultrasound.}

Subcutaneous BxPC3 pancreatic cancer tumors were treated either by microbubble-assisted ultrasound on its own (Group 2) (A), or by i.v. administration of one Nab-paclitaxel dose at 5 $\mathrm{mg} / \mathrm{kg}$ of alone (Group 3) or in combination with BG8214 microbubble-assisted ultrasound (Group 4) (B), by i.v. injection of one Nab-paclitaxel dose at $20 \mathrm{mg} / \mathrm{kg}$ on its own (Group 5) or in combination with microbubble-assisted ultrasound using BG8214 (Group 6) or BG8610 (Group 7) microbubbles (C). The therapeutic effectiveness of Nab-paclitaxel delivery by microbubble-assisted ultrasound was monitored using anatomical ultrasound imaging every 3 day before the treatment. Data expressed as mean \pm SEM were calculated from 8-10 tumors. Significance was defined as $p<0.05\left({ }^{*} p<0.05 ;{ }^{\#} p<0.05\right.$; Mann-Whitney test $)$.

A

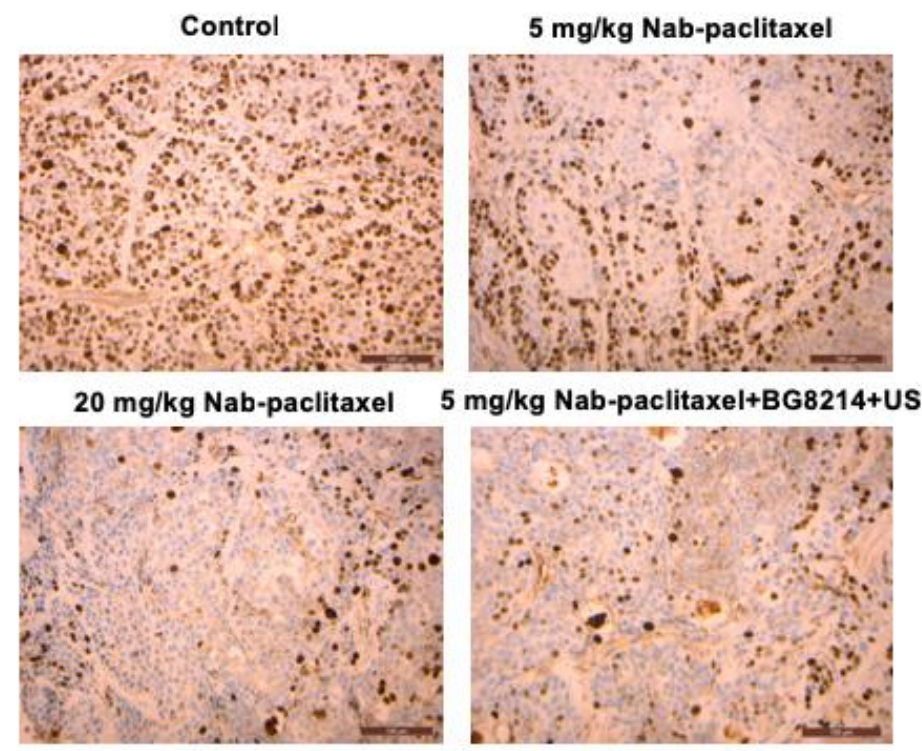

B

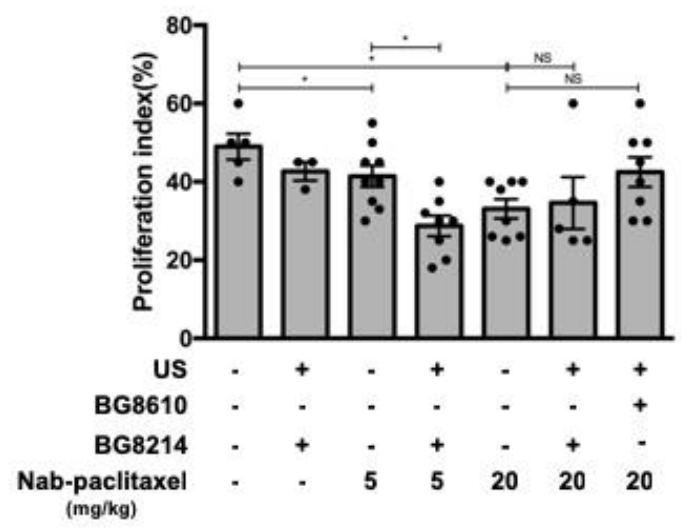




\section{Figure 3. Proliferation staining using Ki-67 immunohistochemistry of BxPC3 tumor}

sections. (A) Representative images of BxPC3 tumors where significant difference was observed between these experimental groups. (B) Quantitative analysis of tumor proliferation. Data expressed as mean \pm SEM were calculated from 5-9 tumors. Significance was defined as $p<0.05(* p<0.05 ;$ Mann-Whitney test).

To confirm the therapeutic effectiveness of Nab-paclitaxel delivery using microbubbleassisted ultrasound, histopathological analyses were carried out at the end of the therapeutic protocol. The pathologist considered the quality of the tissue sections, accountability, placement and slide labeling adequate for our study. Main difference in histological characteristics between the seven experimental groups laid in the proliferation and necrosis indices. Indeed, the repeated delivery of one Nab-paclitaxel dose at 5 (Group 3) and $20 \mathrm{mg} / \mathrm{kg}$ (Group 5) on its own induced a significant $10 \%$ and $20 \%$ decrease in proliferation index compared to the control group, respectively (Figure 3; $p<0.05$ ).

However, as shown in the Figure 4, the control tumors showed high and significant necrosis index in comparison to tumors treated with a Nab-paclitaxel dose at 5 (Group 3) or $20 \mathrm{mg} / \mathrm{kg}$ (Group 5) (54 $\pm 6 \%$ vs $11 \pm 4 \%$ or $0 \%$, respectively; $p<0.05)$. In addition, the repeated delivery of one Nab-paclitaxel dose at $5 \mathrm{mg} / \mathrm{kg}$ in combination with BG8214 microbubble-assisted ultrasound led to significant decrease in proliferation index in comparison to the $5 \mathrm{mg} / \mathrm{kg}$ Nabpaclitaxel treatment alone (Figure 3; Group 3 vs Group 4; $p<0.05$ ). This result suggests a dose-effect of the Nab-paclitaxel on the tumor proliferation. However, no significant difference in necrosis index was observed between the delivery of one Nab-paclitaxel dose at $5 \mathrm{mg} / \mathrm{kg}$ on its own and in combination with BG8214 microbubble-assisted ultrasound (Figure 4; Group 3 $v s$ Group $4 ; p>0.05)$. In addition, the proliferation and necrosis index did not significantly change between the delivery of one Nab-paclitaxel dose at $20 \mathrm{mg} / \mathrm{kg}$ on its own and in 
combination with BG8214 or BG8610 microbubble-assisted ultrasound (Figures 3 and 4; Groups 6 and 7 vs Group 5; $p<0.05)$.

A
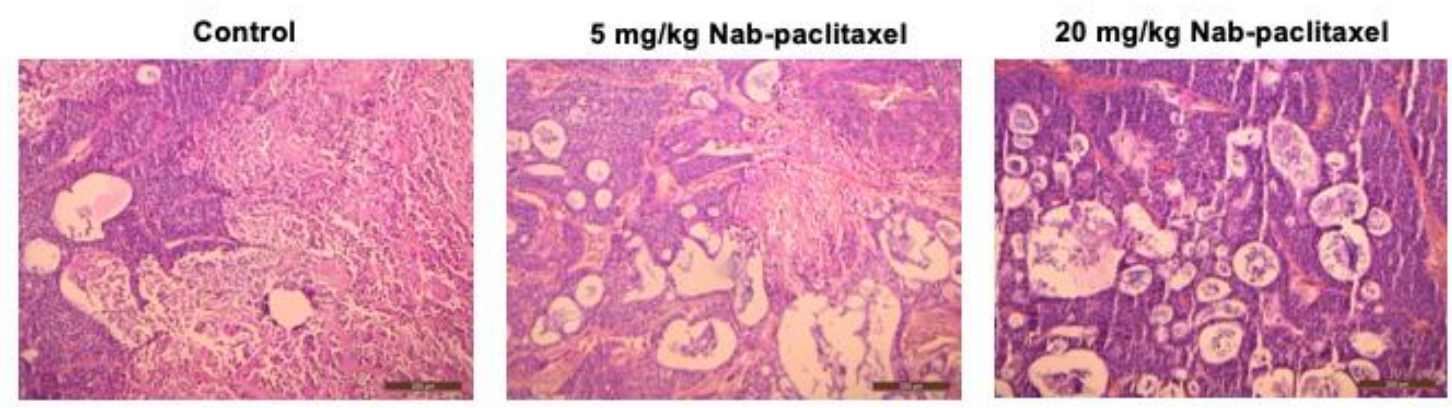

B

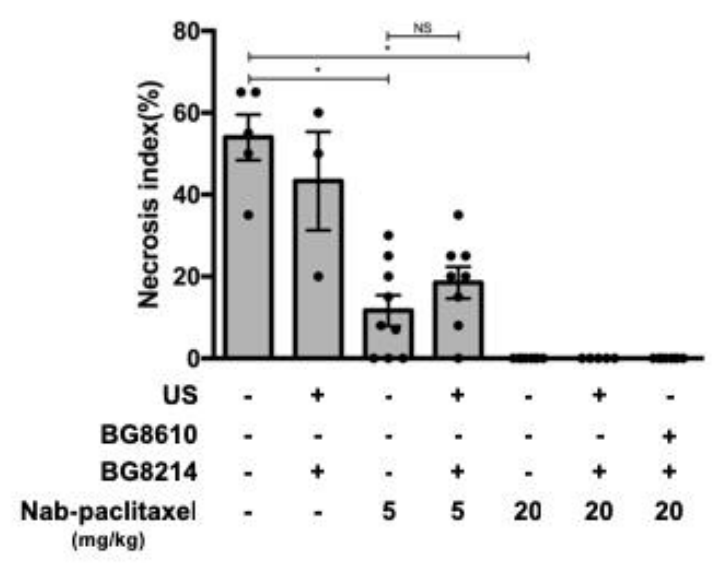

Figure 4. Assessment of tumor necrosis using H\&E staining of BxPC3 tumor sections. (A)

Representative images of BxPC3 tumors where significant difference was observed between these experimental groups. (B) Quantitative analysis of tumor necrosis. Data expressed as mean \pm SEM were calculated from 5-9 tumors. Significance was defined as $p<0.05\left({ }^{*} p<0.05\right.$; Mann-Whitney test).

\section{Mouse quality of life}

The assessment of mouse behavior and body weight showed that no adverse effect was observed when the subcutaneous tumors were treated with BG8214 microbubble-assisted ultrasound on its own in comparison to control group (Figure 5A; Group 2 vs Group 1; $p>0.05$ ). In addition, the repeated i.v. administration of one Nab-paclitaxel dose at $5 \mathrm{mg} / \mathrm{kg}$ in combination with or without BG8214 microbubble-assisted ultrasound did not change the 
mouse behavior and body weight compared to control group (Figure 5B; Group 4 vs Group 3; $p>0.05)$.

However, the repeated i.v. injection of one Nab-paclitaxel dose at $20 \mathrm{mg} / \mathrm{kg}$ induced a significant decrease in body weight (Figure 5C; Group 5 vs Group $1 ; p<0.05$ ) and overall deterioration of mouse health status, thus suggesting such treatment induced systemic toxicity. Interestingly, the repeated delivery of one Nab-paclitaxel dose at $20 \mathrm{mg} / \mathrm{kg}$ using microbubbleassisted ultrasound (BG8214 or BG8610) slowed down the body weight loss related to systemic toxicity of such drug dose (Figure 5; Groups 6 and 7 vs Group 5).

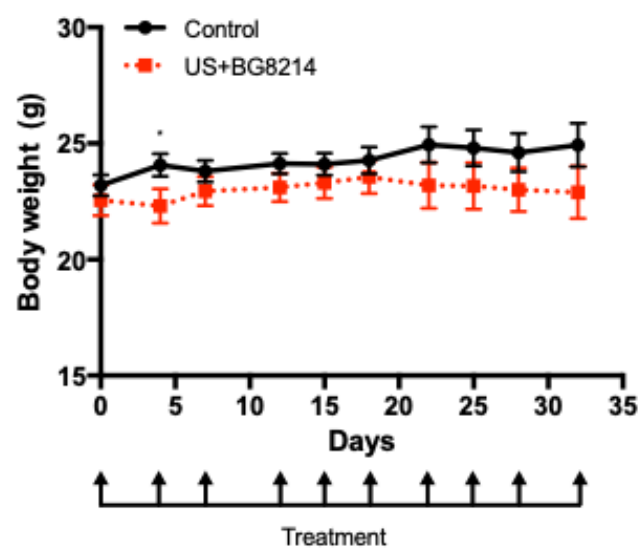

B

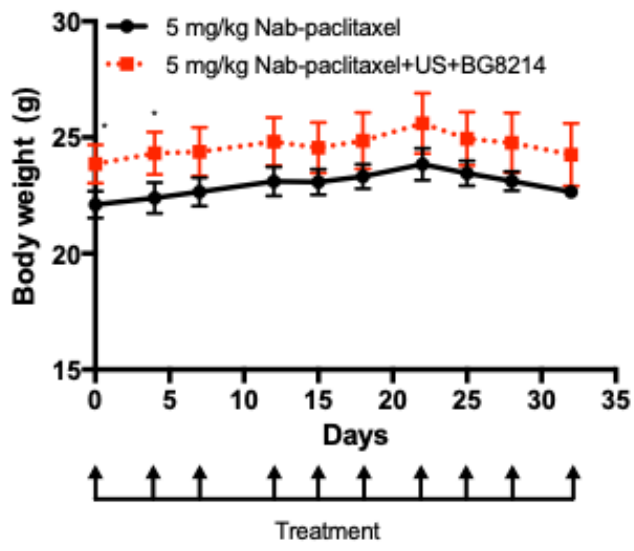

C

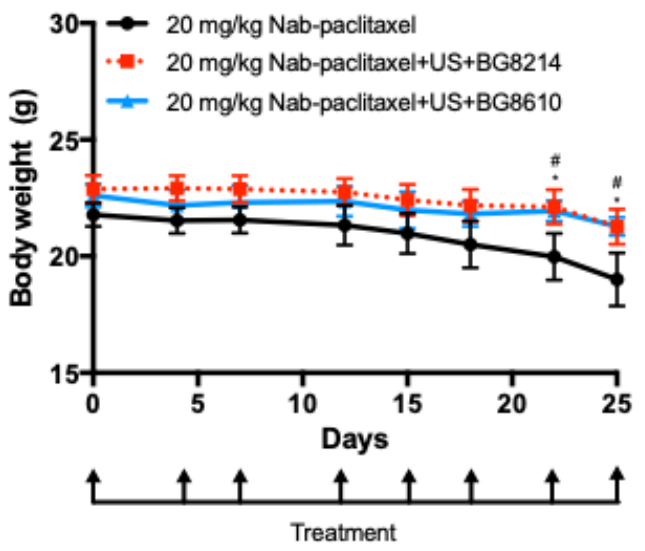

Figure 5. Effect(s) of in-vivo acoustically-mediated Nab-paclitaxel delivery on mouse body weight. Data expressed as mean \pm SEM were calculated from 8-10 mice. Significance was defined as $p<0.05\left({ }^{*} p<0.05 ;{ }^{\#} p<0.05\right.$; Mann-Whitney test $)$. 


\section{DISCUSSION}

The present study investigated the therapeutic benefit of in-vitro and in-vivo Nab-paclitaxel delivery using microbubble-assisted ultrasound. First, in-vitro results demonstrated that the acoustically-mediated Nab-paclitaxel delivery led to a significant decrease in cell viability of human pancreatic cancer cells in comparison with Nab-paclitaxel treatment on its own (Figure 2A). In agreement with previous studies, these results demonstrated indirectly that the increase in cell death could be ascribed to an enhanced intracellular uptake of Nab-paclitaxel or paclitaxel released from Nab-paclitaxel through acoustically-induced hydrophilic pores ${ }^{40,41}$. In comparison to other low molecular weight chemotherapeutic drugs, Nab-paclitaxel is a nanoparticle-based drug with a size of approximately $130 \mathrm{~nm}$. The present study hence demonstrated that ultrasound in combination with microbubbles is capable of increasing the intracellular uptake of much larger molecules (e.g., nanoparticles). Indeed, these investigations reported that the microbubble-assisted ultrasound transiently increases the native permeability of plasma membrane of cancer cells through the generation of transient membrane pores with a size ranging from 10 to $200 \mathrm{~nm}^{21,42}$. The intracellular uptake of nanoparticles (e.g., Nabpaclitaxel) and low molecular weight drugs (e.g., paclitaxel) is governed by passive diffusion through membrane nanopores ${ }^{43,44}$. Thus, these compounds accessed directly (i.e., free access) into the cytoplasm of cancer cells.

Subsequently, we described that the therapeutic effectiveness of in-vitro acousticallymediated Nab-paclitaxel delivery was dependent on the type of microbubbles. Indeed, BG8214 microbubbles are more efficient than BG8610 microbubbles for Nab-paclitaxel-induced cell death, with the ultrasound settings applied in this study (Figure 1A). In addition, the BG8214 microbubbles are as effective as BG8610 microbubbles for increasing the intracellular uptake of fluorescent nanoparticles (as Nab-paclitaxel model drug) (Figure 1B) while the former ones are the most efficient microbubbles for enhancing the intracellular incorporation of propidium 
iodide (as low molecular weight model drug) (Figure 1C). These results are in agreement with previous studies, which reported that the effectiveness of the acoustically-mediated membrane permeabilization and intracellular drug delivery were dependent on the microbubble related parameters (e.g., size, shell composition, gas and concentration $)^{45-47}$. Indeed, these parameters control the acoustic properties of the microbubbles and influence the microbubble response to the ultrasound excitation ${ }^{14}$. The exposure of different microbubble types to the same ultrasound conditions should result in different acoustic phenomena (e.g., acoustic microstreaming, shock waves and microjets) that could differently permeabilize the plasma membrane of nearby cancer cells and therefore, increase the intracellular incorporation of anti-cancer drugs. Our results suggest that under ultrasound exposure, BG8610 and BG8214 microbubbles should generate two classes of membrane pores. Indeed, Figure 1B shows that both microbubbles induced the formation of large membrane pores (i.e., > $100 \mathrm{~nm}$ ), allowing the intracellular uptake of nanoparticles as well as small molecules (Figure 1C). In addition, Figure 1C indicates that both microbubbles led to the creation of small membrane pores (i.e., $<100 \mathrm{~nm}$ ) through which only small molecules (e.g., propidium iodide) enter into the cells. The statistical difference observed in the intracellular incorporation of propidium iodide between both microbubbles (Figure 1C) suggest that BG8214 microbubbles might generate higher number of small membrane pores than BG8610 microbubbles. However, one cannot exclude that both microbubbles created similar number of small membrane pores with different lifetimes. Indeed, BG8214 microbubbles might create longer-lived membrane pore than BG8610 microbubbles. Further additional investigations will have to confirm these hypotheses.

Subsequently, our preclinical results demonstrated that in-vivo Nab-paclitaxel delivery by microbubble-assisted ultrasound resulted in a significant decrease in tumor growth in comparison to Nab-paclitaxel treatment on its own (Figures 2 and 3). Using BG8214 microbubbles, ultrasound potentiates the therapeutic effectiveness of low (i.e., $5 \mathrm{mg} / \mathrm{kg}$; Group 
4) as well as high (i.e., $20 \mathrm{mg} / \mathrm{kg}$; Groups 6 and 7) dose of Nab-paclitaxel in subcutaneous pancreatic cancer model in nude mouse (Figures 2B and 2C). However, no significant difference in the therapeutic effectiveness was observed between BG8214 and BG8610 microbubbles for the delivery of high dose of Nab-paclitaxel (Group 6 vs Group 7). Under our experimental conditions, no adverse side effect due to ultrasound protocol is observed. Nevertheless, systemic administration of $20 \mathrm{mg} / \mathrm{kg} \mathrm{Nab}$-paclitaxel (Group 5) is associated with an overall deterioration of mouse health status. These results were partially confirmed by histological analysis (Figures 3 and 4). Indeed, these last ones did not show any significant difference between tumors treated with i.v. injection of one Nab-paclitaxel dose at $20 \mathrm{mg} / \mathrm{kg}$ on its own (Group 5) or in combination with microbubble-assisted ultrasound (independently of microbubble types; Groups 6 and 7) in proliferation and necrosis indices in comparison with the tumor volume assessed by ultrasound imaging. We hypothesize that HES and Ki67 stainings are not enough sensitive to detect slight but significant difference in tumor response to high dose of Nab-paclitaxel in comparison with the ultrasound imaging. Complementary molecular assays should be considered to analyze tumor response at molecular level in our future investigations. In clinical practice, microbubble-assisted ultrasound is compatible with current administration of Nab-paclitaxel-based chemotherapy protocols ${ }^{4,48}$. This method should be able to increase bioavailability of paclitaxel in the tumor interstitial compartment and to improve its therapeutic effectiveness while minimizing its systemic toxicity (Figure 5) ${ }^{49,50}$. Indeed, the exposure of microbubbles to ultrasound in the tumor microvessels may transiently increase the permeability of tumor endothelium and consequently enhance the extravasation and the intratumoral bioavailability of Nab-paclitaxel or paclitaxel released from Nabpaclitaxel $^{51,52}$. In addition, the acoustically-mediated permeabilization may increase the intracellular uptake of paclitaxel in the endothelial cells. Hence, this method might induce the destruction of tumor vasculature and decrease the supply of nutrients and oxygen in the tumor 
tissues $^{29,53}$. Further additional investigations will have to investigate the in-vivo mechanisms involved in the delivery of Nab-paclitaxel in our mouse model. The extravasation of fluorescent Nab-paclitaxel should be assessed using intravital fluorescence imaging ${ }^{54}$ during the ultrasound protocol and their biodistribution by using histological techniques.

Our preclinical therapeutic protocol is prone to improvements in terms of ultrasound parameters (e.g., acoustic pressure, duty cycle, pulse repetitive frequency, exposure time) and gas bubbles (e.g., dose, nature, type of microbubbles or nanobubbles). In addition, further additional investigations including the drug biodistribution and pharmacokinetics studies will have to confirm that the increase in therapeutic effectiveness of anti-cancer drugs is correlated with enhanced intratumoral accumulation of $\operatorname{drugs}^{23}$. To demonstrate the safety of this promising method, drug biodistribution towards healthy tissues should be examined and physiological functions of healthy organs should be evaluated using imaging modalities, histological and blood biochemistry analyses. These aspects need to be integrated in future studies in orthotopic pancreatic cancer model in mice.

The present study showed that Nab-paclitaxel delivery using microbubble-assisted ultrasound enhanced the in-vitro and in-vivo therapeutic effectiveness of paclitaxel in comparison with Nab-paclitaxel treatment on its own. Nevertheless, further developments are still required to potentiate this therapeutic protocol. Microbubble-assisted ultrasound might be a great method to improve the efficiency of current chemotherapy while minimizing the systemic side effects.

\section{ACKNOWLEDGMENTS}

We acknowledge Prof. F.X. Caroli-Bosc (Department of Hepato-gastro-enterology and digestive oncology, CHRU d'Angers, Angers, France), Dr. J.F. Tournamille (Regional Center of Cancerology, Henry Kaplan, CHRU de Tours, Tours, France), Mrs Schubnel and Mr. Aubert (PST Animalerie, Université de Tours). This work was supported by the CANCEN (DB), 
FARE-SNFGE (TL), Ligue Contre le Cancer (AB), Inserm (AB) and Cancéropôle Grand-Ouest

(TL) grants.

\section{REFERENCES}

1. Ferlay, J.; Soerjomataram, I.; Dikshit, R.; Eser, S.; Mathers, C.; Rebelo, M.; Parkin, D. M.; Forman, D.; Bray, F. Cancer incidence and mortality worldwide: sources, methods and major patterns in GLOBOCAN 2012. Int J Cancer 2015, 136, (5), E359-86.

2. Malvezzi, M.; Bertuccio, P.; Rosso, T.; Rota, M.; Levi, F.; La Vecchia, C.; Negri, E. European cancer mortality predictions for the year 2015: does lung cancer have the highest death rate in EU women? Ann Oncol 2015, 26, (4), 779-86.

3. Ferlay, J.; Partensky, C.; Bray, F. More deaths from pancreatic cancer than breast cancer in the EU by 2017. Acta Oncol 2016, 55, (9-10), 1158-1160.

4. Giordano, G.; Pancione, M.; Olivieri, N.; Parcesepe, P.; Velocci, M.; Di Raimo, T.; Coppola, L.; Toffoli, G.; D'Andrea, M. R. Nano albumin bound-paclitaxel in pancreatic cancer: Current evidences and future directions. World J Gastroenterol 2017, 23, (32), 5875-5886.

5. Von Hoff, D. D.; Ramanathan, R. K.; Borad, M. J.; Laheru, D. A.; Smith, L. S.; Wood, T. E.; Korn, R. L.; Desai, N.; Trieu, V.; Iglesias, J. L.; Zhang, H.; Soon-Shiong, P.; Shi, T.; Rajeshkumar, N. V.; Maitra, A.; Hidalgo, M. Gemcitabine plus nab-paclitaxel is an active regimen in patients with advanced pancreatic cancer: a phase I/II trial. J Clin Oncol 2011, 29, (34), 4548-54.

6. Von Hoff, D. D.; Ervin, T.; Arena, F. P.; Chiorean, E. G.; Infante, J.; Moore, M.; Seay, T.; Tjulandin, S. A.; Ma, W. W.; Saleh, M. N.; Harris, M.; Reni, M.; Dowden, S.; Laheru, D.; Bahary, N.; Ramanathan, R. K.; Tabernero, J.; Hidalgo, M.; Goldstein, D.; Van Cutsem, E.; Wei, X.; Iglesias, J.; Renschler, M. F. Increased survival in pancreatic cancer with nabpaclitaxel plus gemcitabine. $N$ Engl J Med 2013, 369, (18), 1691-703.

7. Conroy, T.; Desseigne, F.; Ychou, M.; Bouche, O.; Guimbaud, R.; Becouarn, Y.; Adenis, A.; Raoul, J. L.; Gourgou-Bourgade, S.; de la Fouchardiere, C.; Bennouna, J.; Bachet, J. B.; Khemissa-Akouz, F.; Pere-Verge, D.; Delbaldo, C.; Assenat, E.; Chauffert, B.; Michel, P.; Montoto-Grillot, C.; Ducreux, M.; Groupe Tumeurs Digestives of, U.; Intergroup, P. FOLFIRINOX versus gemcitabine for metastatic pancreatic cancer. $N$ Engl J Med 2011, 364, (19), 1817-25.

8. Gunturu, K. S.; Yao, X.; Cong, X.; Thumar, J. R.; Hochster, H. S.; Stein, S. M.; Lacy, J. FOLFIRINOX for locally advanced and metastatic pancreatic cancer: single institution retrospective review of efficacy and toxicity. Med Oncol 2013, 30, (1), 361.

9. Papadatos-Pastos, D.; Thillai, K.; Rabbie, R.; Ross, P.; Sarker, D. FOLFIRINOX - a new paradigm in the treatment of pancreatic cancer. Expert Rev Anticancer Ther 2014, 14, (10), 1115-25.

10. Dimcevski, G.; Kotopoulis, S.; Bjanes, T.; Hoem, D.; Schjott, J.; Gjertsen, B. T.; Biermann, M.; Molven, A.; Sorbye, H.; McCormack, E.; Postema, M.; Gilja, O. H. A human clinical trial using ultrasound and microbubbles to enhance gemcitabine treatment of inoperable pancreatic cancer. J Control Release 2016, 243, 172-181.

11. Zhang, Y.; Chang, S.; Sun, J.; Zhu, S.; Pu, C.; Li, Y.; Zhu, Y.; Wang, Z.; Xu, R. X. Targeted Microbubbles for Ultrasound Mediated Short Hairpin RNA Plasmid Transfection to Inhibit Survivin Gene Expression and Induce Apoptosis of Ovarian Cancer A2780/DDP Cells. Mol Pharm 2015, 12, (9), 3137-45.

12. Hirabayashi, F.; Iwanaga, K.; Okinaga, T.; Takahashi, O.; Ariyoshi, W.; Suzuki, R.; Sugii, M.; Maruyama, K.; Tominaga, K.; Nishihara, T. Epidermal growth factor receptor- 
targeted sonoporation with microbubbles enhances therapeutic efficacy in a squamous cell carcinoma model. PLoS One 2017, 12, (9), e0185293.

13. Sennoga, C. A.; Kanbar, E.; Auboire, L.; Dujardin, P. A.; Fouan, D.; Escoffre, J. M.; Bouakaz, A. Microbubble-mediated ultrasound drug-delivery and therapeutic monitoring. Expert Opin Drug Deliv 2017, 14, (9), 1031-1043.

14. Shpak, O.; Verweij, M.; de Jong, N.; Versluis, M. Droplets, Bubbles and Ultrasound Interactions. Adv Exp Med Biol 2016, 880, 157-74.

15. Doinikov, A. A.; Bouakaz, A. Acoustic microstreaming around a gas bubble. J Acoust Soc Am 2010, 127, (2), 703-9.

16. $\mathrm{Wu}, \mathrm{J}$. Theoretical study on shear stress generated by microstreaming surrounding contrast agents attached to living cells. Ultrasound Med Biol 2002, 28, (1), 125-9.

17. Junge, L.; Ohl, C. D.; Wolfrum, B.; Arora, M.; Ikink, R. Cell detachment method using shock-wave-induced cavitation. Ultrasound Med Biol 2003, 29, (12), 1769-76.

18. Ohl, C. D.; Wolfrum, B. Detachment and sonoporation of adherent HeLa-cells by shock wave-induced cavitation. Biochim Biophys Acta 2003, 1624, (1-3), 131-8.

19. Ohl, C. D.; Arora, M.; Ikink, R.; de Jong, N.; Versluis, M.; Delius, M.; Lohse, D. Sonoporation from jetting cavitation bubbles. Biophys J 2006, 91, (11), 4285-95.

20. Postema, M.; van Wamel, A.; ten Cate, F. J.; de Jong, N. High-speed photography during ultrasound illustrates potential therapeutic applications of microbubbles. Med Phys 2005, $32,(12), 3707-11$.

21. Lentacker, I.; De Cock, I.; Deckers, R.; De Smedt, S. C.; Moonen, C. T. Understanding ultrasound induced sonoporation: definitions and underlying mechanisms. Adv Drug Deliv Rev 2014, 72, 49-64.

22. Zeghimi, A.; Escoffre, J. M.; Bouakaz, A. Role of endocytosis in sonoporationmediated membrane permeabilization and uptake of small molecules: a electron microscopy study. Phys Biol 2015, 12, (6), 066007.

23. Lammertink, B. H.; Bos, C.; Deckers, R.; Storm, G.; Moonen, C. T.; Escoffre, J. M. Sonochemotherapy: from bench to bedside. Front Pharmacol 2015, 6, 138.

24. Kotopoulis, S.; Delalande, A.; Popa, M.; Mamaeva, V.; Dimcevski, G.; Gilja, O. H.; Postema, M.; Gjertsen, B. T.; McCormack, E. Sonoporation-enhanced chemotherapy significantly reduces primary tumour burden in an orthotopic pancreatic cancer xenograft. $\mathrm{Mol}$ Imaging Biol 2014, 16, (1), 53-62.

25. Yu, M. H.; Lee, J. Y.; Kim, H. R.; Kim, B. R.; Park, E. J.; Kim, H. S.; Han, J. K.; Choi, B. I. Therapeutic Effects of Microbubbles Added to Combined High-Intensity Focused Ultrasound and Chemotherapy in a Pancreatic Cancer Xenograft Model. Korean J Radiol 2016, $17,(5), 779-88$.

26. Kotopoulis, S.; Dimcevski, G.; Gilja, O. H.; Hoem, D.; Postema, M. Treatment of human pancreatic cancer using combined ultrasound, microbubbles, and gemcitabine: a clinical case study. Med Phys 2013, 40, (7), 072902.

27. Neesse, A.; Michl, P.; Tuveson, D. A.; Ellenrieder, V. nab-Paclitaxel: novel clinical and experimental evidence in pancreatic cancer. $Z$ Gastroenterol 2014, 52, (4), 360-366.

28. Arthuis, C. J.; Novell, A.; Escoffre, J. M.; Patat, F.; Bouakaz, A.; Perrotin, F. New insights into uteroplacental perfusion: quantitative analysis using Doppler and contrastenhanced ultrasound imaging. Placenta 2013, 34, (5), 424-31.

29. Escoffre, J. M.; Novell, A.; Serriere, S.; Lecomte, T.; Bouakaz, A. Irinotecan delivery by microbubble-assisted ultrasound: in vitro validation and a pilot preclinical study. Mol Pharm 2013, 10, (7), 2667-75.

30. Schneider, M.; Anantharam, B.; Arditi, M.; Bokor, D.; Broillet, A.; Bussat, P.; Fouillet, X.; Frinking, P.; Tardy, I.; Terrettaz, J.; Senior, R.; Tranquart, F. BR38, a new ultrasound blood pool agent. Invest Radiol 2011, 46, (8), 486-94. 
31. Escoffre, J. M.; Bellard, E.; Faurie, C.; Sebai, S. C.; Golzio, M.; Teissie, J.; Rols, M. P. Membrane disorder and phospholipid scrambling in electropermeabilized and viable cells. Biochim Biophys Acta 2014, 1838, (7), 1701-9.

32. Mukherjee, P.; S.S.P., N.; Kessler, J. A.; Espinosa, H. D. Combined Numerical and Experimental Investigation of Localized Electroporation-Based Cell Transfection and Sampling. ACS Nano 2018, 12, (12), 12118-12128.

33. Zeghimi, A.; Novell, A.; Thepault, R. A.; Vourc'h, P.; Bouakaz, A.; Escoffre, J. M. Serum influence on in-vitro gene delivery using microbubble-assisted ultrasound. $J$ Drug Target 2014, 22, (8), 748-60.

34. Escoffre, J. M.; Piron, J.; Novell, A.; Bouakaz, A. Doxorubicin delivery into tumor cells with ultrasound and microbubbles. Mol Pharm 2011, 8, (3), 799-806.

35. Dagher, J.; Delahunt, B.; Rioux-Leclercq, N.; Egevad, L.; Coughlin, G.; Dunglison, N.; Gianduzzo, T.; Kua, B.; Malone, G.; Martin, B.; Preston, J.; Pokorny, M.; Wood, S.; Samaratunga, H. Assessment of tumour-associated necrosis provides prognostic information additional to World Health Organization/International Society of Urological Pathology grading for clear cell renal cell carcinoma. Histopathology 2019, 74, (2), 284)290.

36. Escoffre, J. M.; Derieppe, M.; Lammertink, B.; Bos, C.; Moonen, C. MicrobubbleAssisted Ultrasound-Induced Transient Phosphatidylserine Translocation. Ultrasound Med Biol 2017, 43, (4), 838-851.

37. van Rooij, T.; Skachkov, I.; Beekers, I.; Lattwein, K. R.; Voorneveld, J. D.; Kokhuis, T. J. A.; Bera, D.; Luan, Y.; van der Steen, A. F. W.; de Jong, N.; Kooiman, K. Viability of endothelial cells after ultrasound-mediated sonoporation: Influence of targeting, oscillation, and displacement of microbubbles. J Control Release 2016, 238, 197-211.

38. Derieppe, M.; de Senneville, B. D.; H., K.; Moonen, C.; Bos, C. Tracking of cell nuclei for assessment of in vitro uptake kinetics in ultrasound-mediated drug delivery using fibered confocal fluorescence microscopy. Mol Imaging Biol 2014, 16, (5), 642-51.

39. Juffermans, L. J.; van Dijk, A.; Jongenelen, C. A.; Drukarch, B.; Reijerkerk, A.; de Vries, H. E.; Kamp, O.; Musters, R. J. Ultrasound and microbubble-induced intra- and intercellular bioeffects in primary endothelial cells. Ultrasound Med Biol 2009, 35, (11), 191727.

40. Geers, B.; Lentacker, I.; Alonso, A.; Sanders, N. N.; Demeester, J.; Meairs, S.; De Smedt, S. C. Elucidating the mechanisms behind sonoporation with adeno-associated virus-loaded microbubbles. Mol Pharm 2011, 8, (6), 2244-51.

41. De Cock, I.; Zagato, E.; Braeckmans, K.; Luan, Y.; de Jong, N.; De Smedt, S. C.; Lentacker, I. Ultrasound and microbubble mediated drug delivery: acoustic pressure as determinant for uptake via membrane pores or endocytosis. J Control Release 2015, 197, 20-8. 42. Meijering, B. D.; Juffermans, L. J.; van Wamel, A.; Henning, R. H.; Zuhorn, I. S.; Emmer, M.; Versteilen, A. M.; Paulus, W. J.; van Gilst, W. H.; Kooiman, K.; de Jong, N.; Musters, R. J.; Deelman, L. E.; Kamp, O. Ultrasound and microbubble-targeted delivery of macromolecules is regulated by induction of endocytosis and pore formation. Circ Res 2009, 104, (5), 679-87.

43. Derieppe, M.; Yudina, A.; Lepetit-Coiffe, M.; de Senneville, B. D.; Bos, C.; Moonen, C. Real-time assessment of ultrasound-mediated drug delivery using fibered confocal fluorescence microscopy. Mol Imaging Biol 2013, 15, (1), 3-11.

44. Afadzi, M.; Strand, S. P.; Nilssen, E. A.; Masoy, S. E.; Johansen, T. F.; Hansen, R.; Angelsen, B. A.; Davies, L. C. Mechanisms of the ultrasound-mediated intracellular delivery of liposomes and dextrans. IEEE Trans Ultrason Ferroelectr Freq Control 2013, 60, (1), 2133. 
45. Li, T.; Tachibana, K.; Kuroki, M.; Kuroki, M. Gene transfer with echo-enhanced contrast agents: comparison between Albunex, Optison, and Levovist in mice--initial results. Radiology 2003, 229, (2), 423-8.

46. Kudo, N.; Okada, K.; Yamamoto, K. Sonoporation by single-shot pulsed ultrasound with microbubbles adjacent to cells. Biophys $J$ 2009, 96, (12), 4866-76.

47. Escoffre, J. M.; Novell, A.; Piron, J.; Zeghimi, A.; Doinikov, A.; Bouakaz, A. Microbubble attenuation and destruction: are they involved in sonoporation efficiency? IEEE Trans Ultrason Ferroelectr Freq Control 2013, 60, (1), 46-52.

48. Dadi, N.; Stanley, M.; Shahda, S.; O'Neil, B. H.; Sehdev, A. Impact of Nab-Paclitaxelbased Second-line Chemotherapy in Metastatic Pancreatic Cancer. Anticancer Res 2017, 37, (10), 5533-5539.

49. Yan, F.; Li, L.; Deng, Z.; Jin, Q.; Chen, J.; Yang, W.; Yeh, C. K.; Wu, J.; Shandas, R.; Liu, X.; Zheng, H. Paclitaxel-liposome-microbubble complexes as ultrasound-triggered therapeutic drug delivery carriers. J Control Release 2013, 166, (3), 246-55.

50. $\quad$ Ting, C. Y.; Fan, C. H.; Liu, H. L.; Huang, C. Y.; Hsieh, H. Y.; Yen, T. C.; Wei, K. C.; Yeh, C. K. Concurrent blood-brain barrier opening and local drug delivery using drug-carrying microbubbles and focused ultrasound for brain glioma treatment. Biomaterials 2012, 33, (2), 704-12.

51. Snipstad, S.; Berg, S.; Morch, Y.; Bjorkoy, A.; Sulheim, E.; Hansen, R.; Grimstad, I.; van Wamel, A.; Maaland, A. F.; Torp, S. H.; Davies, C. L. Ultrasound Improves the Delivery and Therapeutic Effect of Nanoparticle-Stabilized Microbubbles in Breast Cancer Xenografts. Ultrasound Med Biol 2017, 43, (11), 2651-2669.

52. Mullick Chowdhury, S.; Lee, T.; Willmann, J. K. Ultrasound-guided drug delivery in cancer. Ultrasonography 2017, 36, (3), 171-184.

53. Lin, C. Y.; Tseng, H. C.; Shiu, H. R.; Wu, M. F.; Chou, C. Y.; Lin, W. L. Ultrasound sonication with microbubbles disrupts blood vessels and enhances tumor treatments of anticancer nanodrug. Int J Nanomedicine 2012, 7, 2143-52.

54. Derieppe, M.; Escoffre, J. M.; Denis de Senneville, B.; van Houtum, Q.; Rijbroek, A.; van der Wurff-Jacobs, K.; Dubois, L.; Bos, C.; Moonen, C. Assessment of Intratumoral Doxorubicin Penetration after Mild Hyperthermia-Mediated Release from Thermosensitive Liposomes. Contrast Media Mol Imaging 2019, 2019, 2645928. 